\title{
Association of ADIPOR1 polymorphisms with bone mineral density in postmenopausal Korean women
}

\author{
Ha Young Kim ${ }^{1 *}$, Joo-Yeon Hwang ${ }^{4 *}$, \\ Bok-Ghee Han ${ }^{4}$, Jong-Young Lee ${ }^{4}$, \\ Eui Kyun Park ${ }^{3,5}$, Beom-Jun Kim ${ }^{2,3}$, \\ Seung Hun Lee ${ }^{2,3}$, Ghi Su Kim ${ }^{2,3}$, \\ Shin-Yoon $\mathrm{Kim}^{3,6,7}$ and Jung-Min Koh ${ }^{2,3,7}$ \\ ${ }^{1}$ Division of Endocrinology and Metabolism \\ Sanbon Medical Center \\ University of Wonkwang College of Medicine \\ Iksan 570-711, Korea \\ ${ }^{2}$ Division of Endocrinology and Metabolism \\ Asan Medical Center \\ University of Ulsan College of Medicine \\ Seoul 138-736, Korea \\ ${ }^{3}$ Skeletal Diseases Genome Research Center \\ Kyungpook National University Hospital \\ Daegu 700-412, Korea \\ ${ }^{4}$ The Center for Genome Science \\ National Institute of Health \\ Seoul 122-701, Korea \\ ${ }^{5}$ Department of Pathology and Regenerative Medicine \\ School of Dentistry \\ ${ }^{6}$ Department of Orthopedic Surgery \\ School of Medicine \\ Kyungpook National University \\ Daegu 700-412, Korea \\ ${ }^{7}$ Corresponding authors: Tel, 82-2-3010-3247; \\ Fax, 82-2-3010-6962; E-mail, jmkoh@ amc.seoul.kr (J.M.K.) \\ Tel, 82-53-420-5635; Fax, 82-53-422-6605; \\ E-mail, syukim@knu.ac.kr (S.Y.K.) \\ *These authors contributed equally to this work. \\ http://dx.doi.org/10.3858/emm.2012.44.6.045
}

Accepted 28 March 2012

Available Online 10 April 2012

Abbreviations: ADIPOR, adiponectin receptor; BMD, bone mineral density; YSM, year since menopause

\begin{abstract}
Adiponectin may affect bone through interactions with two known receptors, adiponectin receptors (ADIPOR) 1 and 2 . We examined the association between poly-
\end{abstract}

morphisms of ADIPOR1 and ADIPOR2 and bone mineral density (BMD) in postmenopausal Korean women. Six polymorphisms in ADIPOR1 and four polymorphisms in ADIPOR2 were selected and genotyped in all study participants $(n=1,329)$. BMD at the lumbar spine and femur neck were measured using dual-energy X-ray absorptiometry. Lateral thoracolumbar (T4-L4) radiographs were obtained for vertebral fracture assessment and the occurrence of non-vertebral fractures examined using self-reported data. $P$ values were adjusted for multiple testing using Bonferroni correction $\left(P^{c o r r}\right)$. ADIPOR1 rs16850799 and rs34010966 polymorphisms were significantly associated with femur neck BMD ( $P^{c o r r}=\mathbf{0 . 0 3 6}$ in the dominant model; $P^{c o r r}=0.024$ and $P^{c o r r}=0.006$ in the additive and dominant models, respectively). Subjects with the rare allele of each polymorphism had lower BMD, and association of rs34010966 with BMD showed a gene dosage effect. However, ADIPOR2 single nucleotide polymorphisms and haplotypes were not associated with BMD at any site. Our results suggest that ADIPOR1 polymorphisms present a useful genetic marker for BMD in postmenopausal Korean women.

Keywords: ADIPOR1 protein, human; ADIPOR2 protein, human; bone density; genetic association studies; Korea; osteoporosis, postmenopausal; polymorphism, single nucleotide

\section{Introduction}

Osteoporosis is a systemic bone disease characterized by low bone mineral density (BMD) and subsequent bone loss, leading to increased risk of fracture (1993). Obesity is strongly correlated with increased bone mineral density (BMD) (Felson et al., 1993), and increase in body weight reduces fracture risk in both genders (De Laet et al., 2005). In particular, the effects of body weight are possibly attributed to both fat mass and lean mass, of which fat mass is more important in postmenopausal women (Reid et al., 1992). Mechanical load forces may contribute to this relationship, along with other factors, such as sex hormones, glucocorticoids and insulin (Reid et al., 
1993; Gennari et al., 2004). Recent studies have suggested that the association of BMD with body weight may also be mediated by hormonal factors secreted by adipocytes, including leptin and adiponectin (Zoico et al., 2003; Jurimae and Jurimae 2007).

Adiponectin is an adipocyte-derived hormone that possibly affects bone. The receptors for adiponectin, $A D I P O R 1$ and $A D I P O R 2$, have been identified on both osteoblasts and osteoclasts (Berner et al., 2004; Shinoda et al., 2006). To date, reports on the effects of adiponectin on bone metabolism have been inconsistent. Adiponectin has been shown to increase osteoblast proliferation and differentiation and inhibit osteoclastogenesis in vitro (Luo et al., 2005; Oshima et al., 2005; Williams et al., 2009). In support of these in vitro data, transient overexpression of adiponectin in mice increased trabecular bone mass and inhibited osteoclast number and bone resorption (Oshima et al., 2005), although conflicting results have also been reported (Shinoda et al., 2006). In contrast to in vitro and animal data, clinical studies have shown an inverse association of adiponectin with BMD in perimenopausal women (Jurimae et al., 2005), diabetic men and women (Lenchik et al., 2003), and elderly men (Basurto et al., 2009). These findings suggest that the receptors, but not adiponectin itself, are important for bone metabolism.

Although the multiple risk factors influence BMD and the pathogenesis of osteoporosis, genetic factors are mainly implicated and account for approximately $50 \%$ to $85 \%$ of the variance in BMD based on twin and family studies (Slemenda et al., 1991; Arden and Spector, 1997). Several genetic epidemiological studies have demonstrated an association of adiponectin and adiponectin receptor polymorphisms with type 2 diabetes and its related phenotypes (Damcott et al., 2005; Stefan et al., 2005). Recently, Lee et al. (2006) demonstrated that the T45G polymorphism of the adiponectin gene is significantly linked to lower lumbar spine BMD in Korean women. However, the issue of whether ADIPOR1 and ADIPOR2 polymorphisms are associated with bone metabolism is yet to be established. In the current study, we investigated the associations of genetic variations in ADIPOR1 and ADIPOR2 with bone mineral density (BMD) and the risk of osteoporotic fracture in postmenopausal women.

\section{Results}

Clinical data and correlations between BMD and age, weight, height, and YSM are listed in Supple- mental Data Table S1. The mean age of participants was $59.1 \pm 7.3 \mathrm{yr}$ (range $45-87 \mathrm{yr}$ ), and mean YSM was $9.7 \pm 7.8 \mathrm{yr}$ (range, 1-42 yr). As expected, age and YSM were inversely correlated with BMD at both the lumbar spine and femur neck regions. Weight and height were positively correlated with BMD at both sites.

On the basis of the direct sequencing of DNA from 24 Korean individuals, we identified 18 and 17 sequence variants of ADIPOR1 and ADIPOR2, respectively (Figure 1). Among the identified polymorphisms, six SNPs from ADIPOR1 [rs2275737, rs16850799, rs34010966, rs33942950, rs1342387, rs34559546] and four SNPs in ADIPOR2 [rs1029629, -63442G > C, rs12342, rs1044471] were selected for larger-scale genotyping based on minor allele frequency (MAF $\geq 0.1)$, LDs, and haplotype-tagging status. The genotype frequencies of all SNPs analyzed are shown in Supplemental Data Table S2. All genotype distributions were in Hardy-Weinberg equilibrium $(P>0.05)$. For ADIPOR1, two haplotype blocks were constructed using Haploview version 3.2 (Barrett et al., 2005) and Lewontin's method, while one block was constructed for ADIOPR2. Three common haplotypes (frequency $>0.1$ ) in each block were investigated in detail.

Next, the association of ADIPOR1 and ADIPOR2 polymorphisms with BMD at the lumbar spine and femur neck was analyzed. In linear regression analysis adjusted for confounding variables, two SNPS of ADIPOR1 were significantly associated with BMD at the femur neck, even after Bonferroni correction was strictly adopted for multiple comparisons (Table 1). Specifically, ADIPOR1 rs16850799 and rs34010966 were significantly associated with femur neck BMD ( $P^{\text {corr }}=0.036$ in the dominant model; $P^{\text {corr }}=0.024$ and $P^{\text {corr }}=0.006$ in the additive and dominant model, respectively). The effects of ADIPOR1 rs16850799 on BMD were gene dose-dependent. Specifically, subjects homozygous for the common rs16850799 allele displayed highest BMD $\left(0.738 \pm 0.126 \mathrm{~g} / \mathrm{cm}^{2}\right)$, while heterozygotes had intermediate BMD $(0.726$ $\pm 0.119 \mathrm{~g} / \mathrm{cm}^{2}$ ) and rare allele homozygotes had the lowest BMD values $\left(0.722 \pm 0.117 \mathrm{~g} / \mathrm{cm}^{2}\right)$. For ADIPOR1 rs34010966, subjects with rare alleles had lower BMD, compared with those with common alleles. Moreover, ADIPOR1 rs34010966 was correlated with BMD at the total femur and Ward's triangle $\left(P^{\text {corr }}=0.030\right.$ in the dominant model and $P^{\text {corr }}=0.018$ in the dominant model, respectively) (Table 2). However, the ADIPOR2 polymorphisms and haplotypes were not associated with BMD at any site.

The genetic effects of ADIPOR1 and ADIPOR2 
A. Map of ADIPOR1 (adiponectin receptor 1) on chromosome 1p36.13-q41 (17.5 kb)

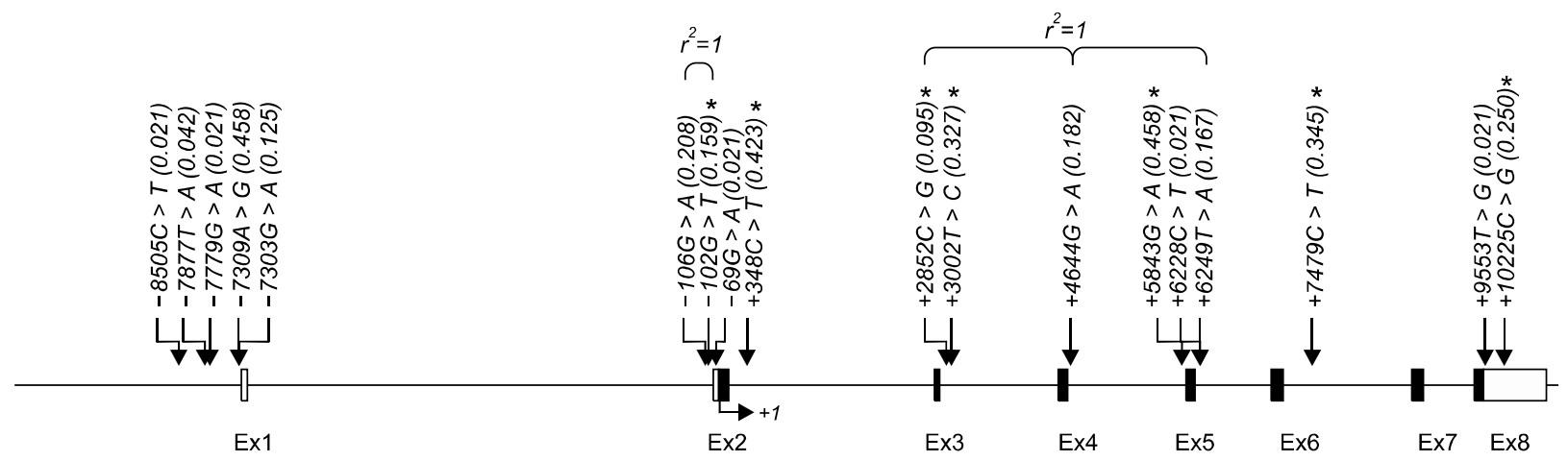

B. Map of ADIPOR2 (adiponectin receptor 2) on chromosome 12p13.31 (97.6 kb)

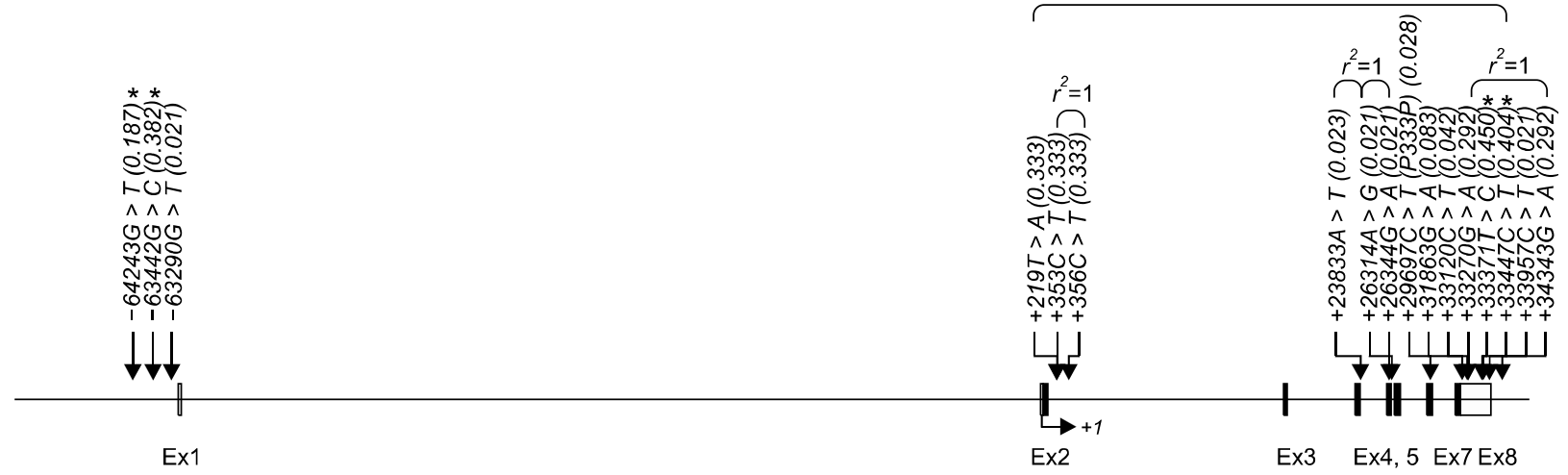

Figure 1. Gene map of the (A) ADIPOR1 and (B) ADIPOR2 genes. Coding exons are marked with black blocks, and $5^{\prime}$ - and $3^{\prime}$-UTRs with white blocks. The first base of the translation start site is designated nucleotide ' +1 '. Asterisks $\left(^{*}\right)$ indicate polymorphisms genotyped in a larger population $(n=1329)$.

polymorphisms on risk of osteoporosis fracture were analyzed using multiple logistic regression analysis adjusted for confounding variables (Table 3). Vertebral and non-vertebral fractures were observed in 99 and 73 subjects, respectively. Despite the significant association of ADIPOR1 $+348 T>C$ and ADIPOR1 rs34010966 with femur neck BMD, no association between these SNPs and osteoporotic fracture was evident. None of the ADIPOR2 polymorphisms or haplotypes were associated with increased risk of any type of osteoporotic fracture.

\section{Discussion}

In the present study, we focused on the genetic association of ADIPOR1 and ADIPOR2 SNPs and haplotypes with postmenopausal osteoporosisrelated phenotypes. Our findings indicate that ADIPOR1 rs16850799 and rs34010966 are significantly associated with femur neck BMD. Interestingly, ADIPOR1 rs34010966 was associated with $\mathrm{BMD}$ at the total femur and Ward's triangle $\left(P^{\text {corr }}=0.030\right.$ in the dominant model and $P^{\text {corr }}=$
0.018 in the dominant model, respectively) However, ADIPOR2 SNPs and haplotypes were not associated with BMD at any site or with any type of osteoporotic fracture. To our knowledge, this is the first clinical report supporting a role for ADIPOR1 and $A D I P O R 2$ polymorphisms on $\mathrm{BMD}$ and fracture risk.

Two SNPs in the intron of ADIPOR1 were associated with femur neck BMD, but not lumbar spine BMD. This site-specific variation of BMD heritability is frequently reported in candidate gene association studies (Yerges et al., 2009). These results may be attributed to different genetic mechanisms of BMDs at different skeletal sites (Videman et al., 2007). At present, the mechanisms through which variants at the ADIPOR1 locus influence bone phenotype are hypothetical. ADIPOR $1+348 T>C$ and $+2852 C>G$ are located within the intron and therefore do not induce amino acid changes. Therefore, it is unclear whether these SNPs are functional or in linkage disequilibrium with an unidentified polymorphism. Moreover, we cannot exclude the possibility that the non-coding intronic polymorphisms mediate genetic function through 


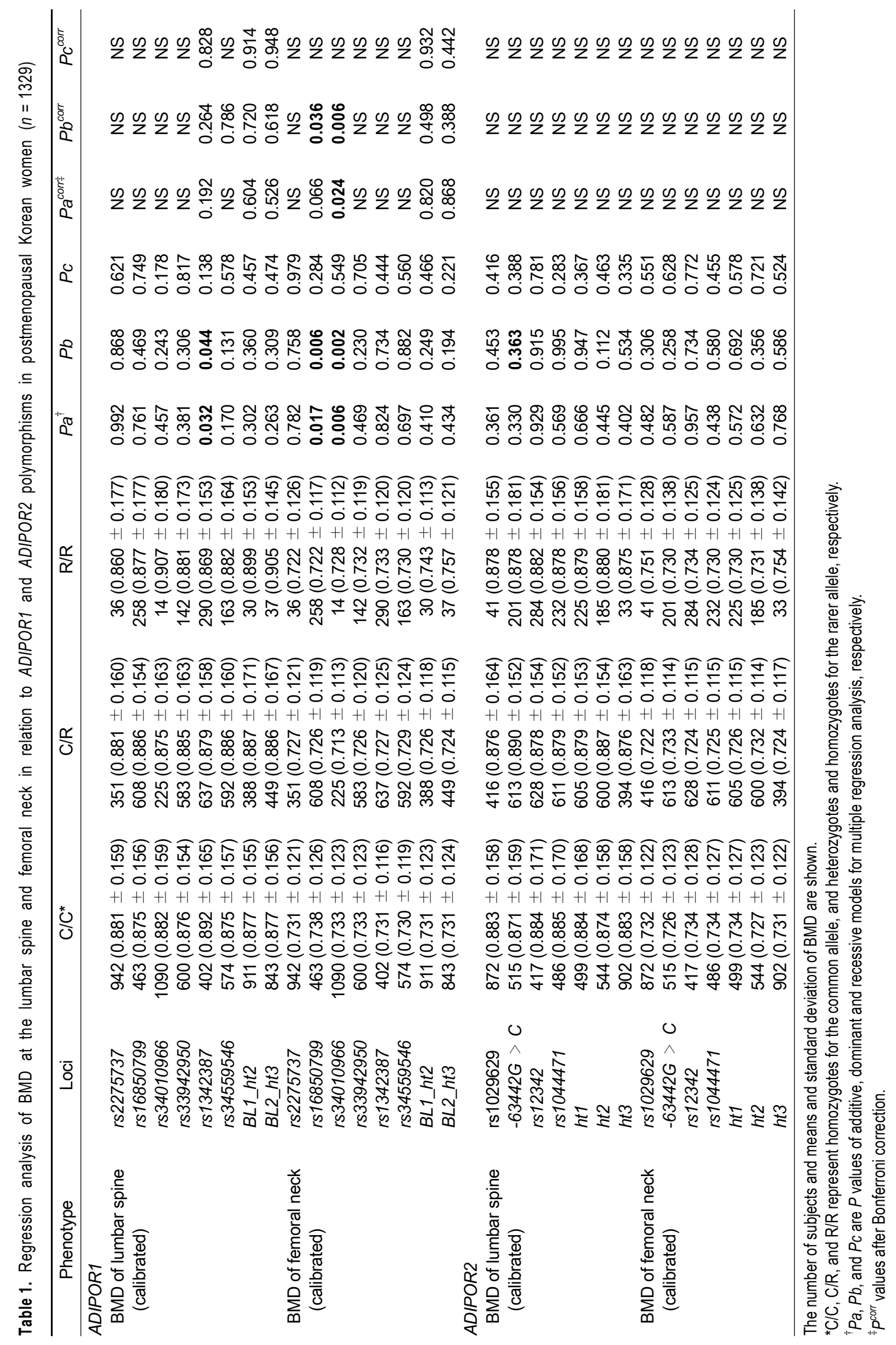




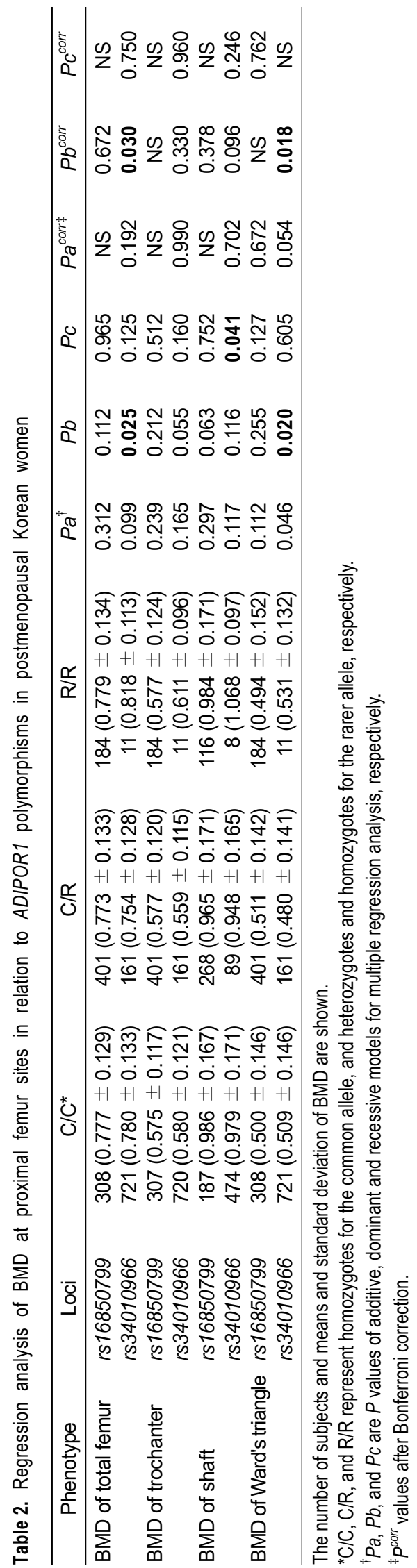

changes in the alternative splicing regimen (Ast, 2004). Notably, SNPs of ADIPOR1, but not those of $A D I P O R 2$, were associated with proximal femur BMDs in our study. These findings suggest that ADIPOR1 is more important for bone biology that ADIPOR2, although both receptors are expressed in bone cells.

Alterations in the expression or conformational changes of the adiponectin receptor associated with SNPs may impair the direct effects of adiponectin on bone. Recently, Soccio et al. (2006) reported that specific ADIPOR1 SNPs linked to increased cardiovascular risk are associated with $30-40 \%$ lower ADIPOR1 mRNA levels in blood mononuclear cells and adipose tissue biopsies. Moreover, the increase in insulin resistance due to impaired adiponectin signaling may indirectly affect bone metabolism, since insulin is a potential regulator of bone (Hickman and McElduff, 1989). Insulin exerts an anabolic effect in bone through direct effects on osteoblast proliferation (Cornish et al., 1996) and indirect effects on the production of sex hormones and their binding globulin (Reid, 2008). A recent study on non-diabetic Mexican Americans has described a strong, positive correlation between ADIPOR 1 expression levels in skeletal muscle and insulin sensitivity, as determined with the glucose clamp (Civitarese et al., 2004). Thus, the association between ADIPOR 1 polymorphisms and bone phenotype may be mediated by an increase in insulin resistance secondary to decreased ADIPOR1 expression resulting from polymorphisms.

Despite the significant association of ADIPOR1 rs16850799 and rs34010966 with BMD at the femur neck, SNPs were not associated with risk of fracture. There may be several explanations for this finding. Firstly, although genetic risk factors are evidently important in the etiology of fracture and BMD (Nguyen et al., 2000), these are likely to be specifically linked to each phenotype. Secondly, some of the additional genetic variants predictive of fracture may affect fracture risk through BMDindependent mechanisms, such as effects on bone geometry, bone matrix and other features of bone quality. Thirdly, fall-related environmental factors, such as postural balance (Pajala et al., 2004), muscle function (Tiainen et al., 2005), and cognitive abilities (Wright et al., 2001), play critical roles in determining fracture risk. Genetic variants related to these factors may contribute to fracture through increased fall risk. Finally, the small number of fractured subjects was insufficient to demonstrate statistical power of association between genotypes and fracture risk. Therefore, a possible role of ADIPOR1 polymorphisms as a genetic marker for bone metabolism cannot be excluded. 
Table 3. Logistic regression analysis of ADIPOR1 and ADIPOR2 polymorphisms in relation to any fracture risk in Korean postmenopausal women

\begin{tabular}{|c|c|c|c|c|c|c|c|c|c|}
\hline \multirow[b]{2}{*}{ Gene } & \multirow[b]{2}{*}{ Loci } & \multicolumn{2}{|c|}{ MAF } & \multicolumn{2}{|c|}{ Co-dominant } & \multicolumn{2}{|c|}{ Dominant } & \multicolumn{2}{|c|}{ Recessive } \\
\hline & & $\begin{array}{l}\text { Any } \\
\text { fracture }\end{array}$ & $\begin{array}{l}\text { No any } \\
\text { fracture }\end{array}$ & OR $(95 \% \mathrm{Cl})$ & $P^{c o r r *}$ & OR (95\%Cl) & $P^{c o r r}$ & OR $(95 \% \mathrm{Cl})$ & $P^{c o r r}$ \\
\hline \multirow[t]{8}{*}{ ADIPOR1 } & $r s 2275737$ & 0.128 & 0.164 & $0.74(0.53-1.05)$ & 0.539 & $0.75(0.51-1.10)$ & 0.821 & $0.40(0.09-1.70)$ & NS \\
\hline & rs16850799 & 0.433 & 0.421 & $1.06(0.84-1.33)$ & NS & $0.97(0.69-1.37)$ & NS & $1.25(0.84-1.87)$ & NS \\
\hline & $r s 34010966$ & 0.101 & 0.094 & $1.08(0.74-1.59)$ & NS & $1.09(0.71-1.67)$ & NS & $1.14(0.25-5.26)$ & NS \\
\hline & rs33942950 & 0.332 & 0.326 & $1.04(0.81-1.34)$ & NS & $1.08(0.78-1.51)$ & NS & $0.98(0.57-1.69)$ & NS \\
\hline & rs1342387 & 0.424 & 0.463 & $0.86(0.68-1.08)$ & NS & $0.87(0.61-1.25)$ & NS & $0.73(0.47-1.12)$ & 0.880 \\
\hline & $r s 34559546$ & 0.348 & 0.345 & $0.99(0.77-1.26)$ & NS & $1.03(0.73-1.44)$ & NS & $0.89(0.53-1.49)$ & NS \\
\hline & BL1_ht2 & 0.204 & 0.164 & $1.37(1.02-1.86)$ & 0.077 & $1.36(0.96-1.92)$ & 0.166 & $2.22(0.92-5.36)$ & 0.152 \\
\hline & BL2_ht3 & 0.229 & 0.192 & $1.33(0.99-1.78)$ & 0.116 & $1.33(0.95-1.87)$ & 0.190 & $1.81(0.77-4.25)$ & 0.350 \\
\hline \multirow[t]{7}{*}{ ADIPOR2 } & rs1029629 & 0.201 & 0.185 & $1.13(0.84-1.52)$ & NS & $1.16(0.82-1.63)$ & NS & $1.06(0.41-2.77)$ & NS \\
\hline & $-63442 G>C$ & 0.427 & 0.376 & $1.24(0.98-1.57)$ & 0.292 & $1.18(0.83-1.66)$ & NS & $1.60(1.05-2.43)$ & 0.110 \\
\hline & rs12342 & 0.399 & 0.457 & $0.79(0.63-1.00)$ & 0.204 & $0.68(0.48-0.96)$ & 0.108 & $0.82(0.54-1.26)$ & NS \\
\hline & rs1044471 & 0.360 & 0.411 & $0.81(0.64-1.03)$ & 0.316 & $0.73(0.52-1.02)$ & 0.247 & $0.81(0.51-1.28)$ & NS \\
\hline & ht1 & 0.354 & 0.403 & $0.81(0.64-1.03)$ & 0.255 & $0.74(0.53-1.04)$ & 0.238 & $0.79(0.49-1.27)$ & 0.979 \\
\hline & $h t 2$ & 0.402 & 0.360 & $1.20(0.94-1.52)$ & 0.412 & $1.19(0.84-1.67)$ & 0.975 & $1.42(0.91-2.21)$ & 0.359 \\
\hline & $h t 3$ & 0.186 & 0.171 & $1.12(0.82-1.53)$ & NS & $1.11(0.78-1.58)$ & NS & $1.39(0.52-3.70)$ & NS \\
\hline
\end{tabular}

Genotype distributions and $P$ values for logistic analyses of three alternative models (additive, dominant and recessive), controlling for age, weight, height, and YSM, as covariates, are shown.

${ }^{*} P^{\text {corr }}$ values after Bonferroni correction.

There are several potential limitations of this study. First, our study population was restricted to persons who visited the university hospital. These subjects may not be representative of the general population, impossibly contributing to selection bias. Second, despite the association of the ADIPOR1 rs16850799 and rs34010966 with femur neck BMD, neither was associated with risk of non-vertebral fracture. However, the heritability of fracture itself has been estimated to lie between 25\% and 35\% (MacGregor et al., 2000), which is much lower than the hereditability of the BMD values (Arden and Spector, 1997). In addition, the genetic component of fracture may ultimately be a combination of polygenic effects, gene-gene and genetic environmental interactions. Further multiple analyses with other possible candidate genes are essential to resolve these complex relationships. Third, we did not assess the functional effects of ADIPOR1 SNP activity, and cannot confirm whether adiponectin receptor activity varies according to the absence or presence of polymorphisms and haplotypes. Therefore, we cannot definitely assert that the genotypes are functionally relevant.

In summary, to establish the possible involvement of genetic polymorphisms of ADIPOR1 and ADIPOR2 in osteoporosis, 10 common sites were genotyped in Korean postmenopausal women. ADIPOR1 rs16850799 and rs34010966 were significantly associated with femur neck BMD, even after Bonferroni correction. Our findings suggest that
ADIPOR1 polymorphisms constitute one of the genetic determinants of BMD in postmenopausal Korean women.

\section{Methods}

\section{Subjects}

The study population comprised 1,329 postmenopausal women of Korean ethnicity who visited Asan Medical Center (AMC, Seoul, Korea). All subject visited our hospital for diagnosis or treatment of osteoporosis spontaneously. Menopause was defined as the absence of menstruation for at least one year and serum follicle-stimulating hormone $(\mathrm{FSH})>30 \mathrm{IU} / \mathrm{l}$. Women with premature menopause (before $40 \mathrm{yr}$ of age) were excluded, along with those taking drugs with a possible effect on bone metabolism for more than 6 months or within the previous 12 months (such as glucocorticoids, sex hormones, bisphosphonate or other treatments for osteoporosis). Subjects suffering from diseases that could affect bone metabolism were additionally excluded. Women with a history of stroke or dementia were excluded from analysis owing to concerns related to their limited physical activity, in addition to patients with osteophyte formation above the fourth grade of the Nathan classification (Nathan et al., 1994) and/or severe facet joint osteoarthritis in the lumbar spine diagnosed using conventional spine radiography. The study was approved by the AMC ethics review committee, and written informed consent was obtained from all subjects. 


\section{BMD measurements}

Areal BMD $\left(\mathrm{g} / \mathrm{cm}^{2}\right)$ of the anterior-posterior lumbar spine (L2-L4) and femur neck was measured in 834 women with dual energy X-ray absorptiometry using Lunar equipment (Lunar, Expert XL with software version 1.90; Madison, $\mathrm{WI})$. In the remaining 495 women, BMD was measured using Hologic equipment (Hologic, QDR 4500-A with software version 4.84, Waltham, MA). Owing to upper extremity dominance, BMD at the proximal femur was measured at non-dominant sites. Short-term in vivo measurement precision of the Lunar and Hologic machines, expressed as coefficient of variation, were $0.82 \%$ and $0.85 \%$ for the lumbar spine, and $1.12 \%$ and $1.20 \%$ for the femur neck, respectively. These values were obtained by scanning 17 volunteers who were not part of the study. Each volunteer underwent five scans on the same day, getting on and off the table between examinations. To derive cross-calibration equations between the two systems, BMD values were measured at the lumbar and femur neck with the two machines in 109 healthy Korean women (55 $\pm 11 \mathrm{yr}$, range $31-75 \mathrm{yr}$ ), and calculated as follows (Jo et al.,1999)

$$
\begin{aligned}
& \text { L2-L4 BMD }\left(\mathrm{g} / \mathrm{cm}^{2}\right): \\
& \quad \text { Lunar }=1.1287 \times \text { Hologic }-0.0027 \\
& \text { Femur neck BMD }\left(\mathrm{g} / \mathrm{cm}^{2}\right): \\
& \text { Lunar }=1.1556 \times \text { Hologic }-0.0182
\end{aligned}
$$

We obtained additional BMD values at other proximal femur sites taken after January 2001. The Hologic machine did not measure BMD at the femur shaft. Therefore, BMD values at the femur shaft and other proximal sites (total femur, trochanter and Ward's triangle) were available for 571 and 893 participants, respectively.

\section{Detection of vertebral and non-vertebral fractures}

We examined prevalent morphological vertebral fracture in all study subjects by obtaining lateral thoracolumbar (T4-L4) radiographs. Vertebral fractures were assessed in accordance with the recommendations of the Working Group on Vertebral Fractures (Kiel, 1995). Radiographs were assessed at AMC by expert radiologists blinded to this study A vertebral fracture was defined quantitatively as more than a $20 \%$ reduction in any measured vertebral height (i.e., anterior, middle, or posterior (Genant et al., 1993). In addition, a history of non-vertebral fracture, including those of hip, wrist, forearm, humerus, rib and pelvis, was obtained using self-administered questionnaires. Fractures that had clearly been caused by major trauma, such as a traffic accident or fall from higher than standing height, were excluded.

\section{Sequencing analysis of ADIPOR1 and ADIPOR2}

We sequenced all exons, including exon-intron boundaries, and the promoter region $(\sim 1.5 \mathrm{~Kb})$ to detect single nucleotide polymorphisms (SNPs) in 24 Korean DNA samples using the ABI PRISM 3730 DNA analyzer (Applied Biosystems, Foster City, CA). Sixteen primer sets were designed for amplification and sequencing analyses based on GenBank sequences (Reference Genome Sequence, ADIPOR1: NT_004671.15, and ADIPOR2: NT_009759.15). Sequence variants were verified with automated sequencing chromatograms. SNPs were detected by multiple sequence alignment using the Phred/Phrap/Consed package and Polyphred (Ewing et al., 1998; Gordon et al., 1998).

\section{SNP Genotyping}

For genotyping of polymorphic sites, amplification primers and MGB probes for TaqMan (Livak, 1999) were designed using Primer Express (Applied Biosystems). One allelic probe was labeled with FAM dye and the other with the fluorescent dye, VIC. PCR was performed using TaqMan Universal Master mix without UNG (Applied Biosystems) with $900 \mathrm{nM}$ primer and $200 \mathrm{nM}$ TaqMan MGB-probe. The reactions were performed in a 384-well format in a total reaction volume of $5 \mu \mathrm{l}$ using $20 \mathrm{ng}$ genomic DNA. The plates were then placed in a thermal cycler (PE 9700, Applied Biosystems) and heated at $50^{\circ} \mathrm{C}$ for 2 min and $95^{\circ} \mathrm{C}$ for $10 \mathrm{~min}$, followed by 40 cycles of $95^{\circ} \mathrm{C}$ for $15 \mathrm{~s}$ and $60^{\circ} \mathrm{C}$ for $1 \mathrm{~min}$. The TaqMan assay plates were then transferred to a Prism 7900HT instrument (Applied Biosystems) and the fluorescence intensity in each well of the plate were read. Fluorescence data files from each plate were analyzed using automated software (SDS 2.1, Applied Biosystems). Genotyping quality control was performed in 44 samples by duplicate checking, and the rate of concordance in duplicates was $100 \%$.

\section{Statistical analysis}

To determine whether individual variants were in equilibrium at each locus in the population (Hardy-Weinberg equilibrium), $\chi^{2}$ tests were applied. We examined Lewontin's $\mathrm{D}^{\prime}\left(\left|\mathrm{D}^{\prime}\right|\right)$ and the linkage disequilibrium (LD) coefficient $\left(\mathrm{r}^{2}\right)$ between all pairs of biallelic loci. Haploview version 3.2 (Whitehead Institute for Biomedical research, Cambridge, MA) was used for the structure of LD block (Barrett et al., 2005). This program uses two-marker expectation maximization to estimate the maximum-likelihood values of the four gamete frequencies from which D' and log of odds (LOD) values are derived. Haplotypes and phase probabilities of all polymorphic sites for haplotypes were calculated for each individual with PHASE software (ver 2.0) using the algorithm developed by Stephens et al. (2001). Individuals with phase probabilities of less than $97 \%$ were excluded from the analysis. The genetic effects of inferred haplotypes were analyzed in a similar way to polymorphisms.

Multiple regression analyses were performed for BMD, controlling for age, yr since menopause (YSM), weight and height as covariates. The genotype and haplotype distributions between subjects with and without vertebral and non-vertebral fractures were additionally analyzed with a logistic regression model controlling for age, YSM, weight and height. Genotypes were assigned codes of 0,1 , and 2 for the additive model, 0,1 , and 1 for the dominant model, and 0,0 , and 1 for the recessive model. $P$ values were adjusted for multiple testing by Bonferroni correction $\left(P^{c o r r}\right)$. All statistical analyses were conducted using SAS (SAS Institute, Cary, NC).

\section{Supplemental data}

Supplemental data include two tables and can be found 
with this article online at http://e-emm.or.kr/article/article files/SP-44-6-05.pdf.

\section{Acknowledgements}

This work was supported by a grant from the Korea Health 21 Research \& Development Project of the Ministry of Health \& Welfare, Republic of Korea (Project No.: A010252).

\section{References}

Consensus development conference: diagnosis, prophylaxis, and treatment of osteoporosis. Am J Med 1993;94:646-50

Arden NK, Spector TD. Genetic influences on muscle strength, lean body mass, and bone mineral density: a twin study. J Bone Miner Res 1997;12:2076-81

Ast G. How did alternative splicing evolve? Nat Rev Genet 2004:5:773-82

Barrett JC, Fry B, Maller J, Daly MJ. Haploview: analysis and visualization of LD and haplotype maps. Bioinformatics 2005;21:263-5

Basurto L, Galvan R, Cordova N, Saucedo R, Vargas C Campos S, Halley E, Avelar F, Zarate A. Adiponectin is associated with low bone mineral density in elderly men. Eur J Endocrinol 2009;160:289-93

Berner HS, Lyngstadaas SP, Spahr A, Monjo M, Thommesen L, Drevon CA, Syversen U, Reseland JE. Adiponectin and its receptors are expressed in bone-forming cells. Bone 2004;35:842-9

Civitarese AE, Jenkinson CP, Richardson D, Bajaj M, Cusi K, Kashyap S, Berria R, Belfort R, DeFronzo RA, Mandarino LJ, Ravussin E. Adiponectin receptors gene expression and insulin sensitivity in non-diabetic Mexican Americans with or without a family history of Type 2 diabetes. Diabetologia 2004;47:816-20

Cornish J, Callon KE, Reid IR. Insulin increases histomorphometric indices of bone formation In vivo. Calcif Tissue Int 1996;59:492-5

Damcott CM, Ott SH, Pollin TI, Reinhart LJ, Wang J, O'Connell JR, Mitchell BD, Shuldiner AR. Genetic variation in adiponectin receptor 1 and adiponectin receptor 2 is associated with type 2 diabetes in the Old Order Amish. Diabetes 2005;54:2245-50

De Laet C, Kanis JA, Oden A, Johanson H, Johnell O, Delmas P, Eisman JA, Kroger H, Fujiwara S, Garnero P, McCloskey EV, Mellstrom D, Melton LJ 3rd, Meunier PJ, Pols HA, Reeve J, Silman A, Tenenhouse A. Body mass index as a predictor of fracture risk: a meta-analysis. Osteoporos Int 2005;16: $1330-8$

Ewing B, Hillier L, Wendl MC, Green P. Base-calling of automated sequencer traces using phred. I. Accuracy assessment. Genome Res 1998;8:175-85

Felson DT, Zhang Y, Hannan MT, Anderson JJ. Effects of weight and body mass index on bone mineral density in men and women: the Framingham study. J Bone Miner Res 1993;8:567-73
Genant HK, Wu CY, van Kuijk C, Nevitt MC. Vertebral fracture assessment using a semiquantitative technique. J Bone Miner Res 1993;8:1137-48

Gennari L, Nuti R, Bilezikian JP. Aromatase activity and bone homeostasis in men. J Clin Endocrinol Metab 2004;89: 5898-907

Gordon D, Abajian C, Green P. Consed: a graphical tool for sequence finishing. Genome Res 1998;8:195-202

Hickman J, McElduff A. Insulin promotes growth of the cultured rat osteosarcoma cell line UMR-106-01: an osteoblast-like cell. Endocrinology 1989;124:701-6

Jo JM, Kim JS, Kim GS, Kim SW, Shin JW, Moon DH, Lee HK. Cross-calibration of bone mineral density between two different dual X-ray absorptiometry systems: hologic QDR 4500-A and lunar EXPERT-XL. Korean J Nucl Med 1999;33: $282-8$

Jurimae J, Rembel K, Jurimae T, Rehand M. Adiponectin is associated with bone mineral density in perimenopausal women. Horm Metab Res 2005;37:297-302

Jurimae $\mathrm{J}$, Jurimae $\mathrm{T}$. Adiponectin is a predictor of bone mineral density in middle-aged premenopausal women. Osteoporos Int 2007;18:1253-9

Kiel D. Assessing vertebral fractures. National Osteoporosis Foundation Working Group on Vertebral Fractures. J Bone Miner Res 1995;10:518-23

Lee WY, Rhee EJ, Oh KW, Kim SY, Jung CH, Yun EJ, Baek $\mathrm{KH}$, Kang MI, Kim SW. Identification of adiponectin and its receptors in human osteoblast-like cells and association of T45G polymorphism in exon 2 of adiponectin gene with lumbar spine bone mineral density in Korean women. Clin Endocrinol (Oxf) 2006;65:631-7

Lenchik L, Register TC, Hsu FC, Lohman K, Nicklas BJ, Freedman BI, Langefeld CD, Carr JJ, Bowden DW. Adiponectin as a novel determinant of bone mineral density and visceral fat. Bone 2003;33:646-51

Livak KJ. Allelic discrimination using fluorogenic probes and the 5 ' nuclease assay. Genet Anal 1999;14:143-9

Luo XH, Guo LJ, Yuan LQ, Xie H, Zhou HD, Wu XP, Liao EY. Adiponectin stimulates human osteoblasts proliferation and differentiation via the MAPK signaling pathway. Exp Cell Res 2005;309:99-109

MacGregor A, Snieder H, Spector TD. Genetic factors and osteoporotic fractures in elderly people. Twin data support genetic contribution to risk of fracture. BMJ 2000;320: 1669-70; author reply 70-1

Nathan M, Pope MH, Grobler LJ. Osteophyte formation in the vertebral column: a review of the etiologic factors--Part II. Contemp Orthop 1994;29:113-9

Nguyen GT, Proctor SE, Sinkowitz-Cochran RL, Garrett DO, Jarvis WR. Status of infection surveillance and control programs in the United States, 1992-1996. Association for Professionals in Infection Control and Epidemiology, Inc. Am $\mathrm{J}$ Infect Control 2000;28:392-400

Oshima K, Nampei A, Matsuda M, Iwaki M, Fukuhara A Hashimoto J, Yoshikawa H, Shimomura I. Adiponectin 
increases bone mass by suppressing osteoclast and activating osteoblast. Biochem Biophys Res Commun 2005; 331:520-6

Pajala S, Era P, Koskenvuo M, Kaprio J, Tolvanen A, Heikkinen E, Tiainen K, Rantanen T. Contribution of genetic and environmental effects to postural balance in older female twins. J Appl Physiol 2004;96:308-15

Reid IR, Ames R, Evans MC, Sharpe S, Gamble G, France JT, Lim TM, Cundy TF. Determinants of total body and regional bone mineral density in normal postmenopausal women--a key role for fat mass. J Clin Endocrinol Metab 1992;75:45-51

Reid IR, Evans MC, Cooper GJ, Ames RW, Stapleton J. Circulating insulin levels are related to bone density in normal postmenopausal women. Am J Physiol 1993;265:E655-9

Reid IR. Relationships between fat and bone. Osteoporos Int 2008;19:595-606

Shinoda Y, Yamaguchi M, Ogata N, Akune T, Kubota N, Yamauchi T, Terauchi Y, Kadowaki T, Takeuchi Y, Fukumoto S, Ikeda T, Hoshi K, Chung UI, Nakamura K, Kawaguchi H. Regulation of bone formation by adiponectin through autocrine/paracrine and endocrine pathways. J Cell Biochem 2006;99:196-208

Slemenda CW, Christian JC, Williams CJ, Norton JA, Johnston CC Jr. Genetic determinants of bone mass in adult women: a reevaluation of the twin model and the potential importance of gene interaction on heritability estimates. J Bone Miner Res 1991;6:561-7

Soccio T, Zhang YY, Bacci S, Mlynarski W, Placha G, Raggio G, Di Paola R, Marucci A, Johnstone MT, Gervino EV, Abumrad NA, Klein S, Trischitta V, Doria A. Common haplotypes at the adiponectin receptor 1 (ADIPOR1) locus are associated with increased risk of coronary artery disease in type 2 diabetes. Diabetes 2006;55:2763-70

Stefan N, Machicao F, Staiger H, Machann J, Schick F,
Tschritter O, Spieth C, Weigert C, Fritsche A, Stumvoll M, Haring HU. Polymorphisms in the gene encoding adiponectin receptor 1 are associated with insulin resistance and high liver fat. Diabetologia 2005;48:2282-91

Stephens M, Smith NJ, Donnelly P. A new statistical method for haplotype reconstruction from population data. Am J Hum Genet 2001;68:978-89

Tiainen K, Sipila S, Alen M, Heikkinen E, Kaprio J, Koskenvuo M, Tolvanen A, Pajala S, Rantanen T. Shared genetic and environmental effects on strength and power in older female twins. Med Sci Sports Exerc 2005;37:72-8

Videman T, Levalahti E, Battie MC, Simonen R, Vanninen E, Kaprio J. Heritability of BMD of femoral neck and lumbar spine: a multivariate twin study of Finnish men. J Bone Miner Res 2007;22:1455-62

Williams GA, Wang Y, Callon KE, Watson M, Lin JM, Lam JB, Costa JL, Orpe A, Broom N, Naot D, Reid IR, Cornish J. In vitro and in vivo effects of adiponectin on bone. Endocrinology 2009;150:3603-10

Wright M, De Geus E, Ando J, Luciano M, Posthuma D, Ono Y, Hansell N, Van Baal C, Hiraishi K, Hasegawa T, Smith G, Geffen G, Geffen L, Kanba S, Miyake A, Martin N, Boomsma D. Genetics of cognition: outline of a collaborative twin study. Twin Res 2001;4:48-56

Yerges LM, Klei L, Cauley JA, Roeder K, Kammerer CM, Moffett SP, Ensrud KE, Nestlerode CS, Marshall LM, Hoffman AR, Lewis C, Lang TF, Barrett-Connor E, Ferrell RE, Orwoll ES, Zmuda JM. High-density association study of 383 candidate genes for volumetric BMD at the femoral neck and lumbar spine among older men. J Bone Miner Res 2009;24: 2039-49

Zoico E, Zamboni M, Adami S, Vettor R, Mazzali G, Tosoni $\mathrm{P}$, Bissoli L, Bosello O. Relationship between leptin levels and bone mineral density in the elderly. Clin Endocrinol (Oxf) 2003:59:97-103 